\title{
Physicochemical properties and stability of Moringa oleifera seed oil-in-water emulsions as affected by different types of polysaccharide and emulsifier
}

\author{
Nor Hayati Ibrahim a, ", Ong Ji Jin a, Nizaha Juhaida Muhamad a, Wan Rosli Wan Ishak b, * \\ a School of Food Science and Technology, Universiti Malaysia Terengganu, 21030 Kuala Nerus, Terengganu, Malaysia \\ b School of Health Sciences, Universiti Sains Malaysia, Health Campus, 16150 Kubang Kerian, Kota Bharu, Kelantan, Malaysia \\ *Corresponding author: yati@umt.edu.my
}

\section{Article history}

Received 28 December 2018

Revised 22 February 2019

Accepted 4 April 2019

Published Online 15 May 2019

\begin{abstract}
Moringa oleifera seed oil is a promising medicinal oil and converting it into a functional food emulsion is of current interest to widen its consumption. This study was aimed to investigate physicochemical properties and stability of $M$. oleifera seed oil-in-water emulsions as affected by interaction between polysaccharide i.e. xanthan gum (XG), guar gum (GG), carboxymethyl cellulose (CMC) and emulsifier i.e. sodium caseinate (NaCas) and whey protein isolate (WPI). Significant $(p<0.05)$ lower $\mathrm{pH}$ values in XG-WPI (4.98) and XG-NaCas (4.72) emulsions were observed as opposed to other emulsions (5.19-5.40). The interaction between XG-WPI and XG-NaCas has resulted in significant $(p<0.05)$ higher apparent viscosity values (at $0.42 \mathrm{~s}^{-1}$ ) of their respective emulsions with 35.10 and $10.75 \mathrm{~Pa}$.s respectively, as compared to other emulsions $(0.35-0.85 \mathrm{~Pa}$.s). These desirable characteristics of $\mathrm{pH}$ and viscosity profile had favoured an excellent creaming stability (no phase separation) of the emulsions. Regardless of emulsifier used, XG emulsions exhibited a significant $(p<0.05)$ higher scavenging activity $(34.84-41.52 \%)$ towards 1,1-diphenyl-2-picrylhydrazyl free radicals than other emulsions. Total oxidation values $(11.18-24.93)$ under an accelerated oxidation period (48 hours, $60^{\circ} \mathrm{C}$ ) were more influenced by peroxide value rather than anisidine value. All WPI emulsions and CMC-NaCas emulsion showed significant $(p<0.05)$ low total oxidation values relative to other emulsions. All emulsions however showed no significant difference in their turbidity loss rate $(1.2-$ $3.3 \times 10^{-3}$. These findings have made possible of producing a good quality of a functional food emulsion based on $M$. oliefera seed oil, particularly when the system was stabilized by XG-WPI. This was mainly due to their positive interaction that has affected on $\mathrm{pH}$ and viscosity of emulsion, which eventually led to a good stability towards creaming and inhibition of lipid oxidation.
\end{abstract}

Keywords: M. oleifera seed oil, polysaccharide, emulsifier, emulsion, properties, stability

\section{INTRODUCTION}

Moringa oleifera Lam. is a member of Moringaceae family that originated from India and it is widely cultivated in many tropical and subtropical regions. It is known as a highly valued plant as almost all parts of the plant are considered edible and believed to have medicinal effects. As reviewed by Udechukwu et al. (2018), a significant number of scientific evident on therapeutic effects (e.g. antiinflammatory, anti-cancer, anti-oxidative, anti-diabetic etc.) of the plant have been documented based on animal studies even though the said effects have yet to be affirmed further in human subjects. Besides leaves, fruits of $M$. oleifera are recently being promoted as a potential source of functional food ingredient. The fruits contain seeds that have high amount of crude fat ranging from 30.36 to $38.37 \%$ (Abdulkadir et al., 2016) with oleic acids that accounted up to $73.5 \%$ (Bhutada et al., 2016), which interestingly making this oil to be comparable to olive oil. Moreover, tocopherols, phenolic compounds, flavonoid compounds and carotenoids are inherently natural antioxidants and bioactive compounds of $M$. oleifera seed oil will help in preventing free radical damage to the tissue as well as performing various physiological functions in the body (Bhatnagar \& Gopala
Krishna, 2013). These bioactive compounds are commonly coextracted with the oil especially when a polar solvent like methanol is used. According to Ghafar et al. (2017), maximum values for total phenolic and flavonoid compounds in a methanolic extract of $M$. oleifera seed oil were 2027.07 (mg gallic acid equivalent/g) and 99.72 (mg quercetin equivalent/g), respectively. However, these natural antioxidants and bioactive molecules are light sensitive and easily oxidized when they are exposed to environment before being consumed. Due to this drawback, most of the medicinal oils containing natural antioxidants such as; walnut oil have been proposed to be incorporated into emulsion system for the oxidative protection (Liu et al., 2016).

Emulsion, a kind of food colloid, is defined as a thermodynamically unstable system where two immiscible liquids are mixed together with either one being dispersed as small droplets in another one (McClement, 2005). In oil-in-water (O/W) emulsion, oil is dispersed as small droplets in aqueous phase by force of homogenization and the droplets will maintain their small size by the aid of emulsifiers including whey protein isolate (WPI) and sodium caseinate (NaCas). Furthermore, to improve stability by manipulating the emulsion rheology (mainly viscosity), various polysaccharides like 
xanthan gum (XG), guar gum (GG) and carboxymethyl cellulose (CMC) are incorporated in the aqueous phase. Somehow, interactions between polysaccharide and emulsifier (or protein) will also greatly affect the rheological properties of the emulsion. As demonstrated by Ercelebi and Ibanoglu (2009), there was a positive interaction effect between GG and WPI towards the flow behaviour and viscoelastic profile of the resultant emulsion. Liu et al. (2012) showed that interaction between $\mathrm{NaCas}$ and $\mathrm{CMC}$ would protect the oil droplets from flocculation and coalescence. Besides that, polysaccharideemulsifier interaction would also benefit to oxidative stability of emulsion, mainly due to viscosity enhancement effect that could reduce prooxidants diffusion into oil droplets (Nayebzadeh et al., 2007). Recently, research in this area has advanced in utilization of polysaccharide-emulsifier interaction in designing food colloids by incorporating bioactive compounds from many promising plant sources (Semenova, 2017). To this date, no such reports have been documented for $M$. oleifera seed $\mathrm{O} / \mathrm{W}$ emulsion system. Thus, this study was undertaken to determine main and interact effects of polysaccharide and emulsifier on the physicochemical properties and stability of $M$. oleifera seed $\mathrm{O} / \mathrm{W}$ emulsions.

\section{EXPERIMENTAL}

\section{Materials}

$M$. oleifera seeds were collected from a controlled botanical garden at Bayan Lepas, Pulau Pinang. Sodium caseinate (NaCas), xanthan gum (XG), guar gum (GG) and carboxymethyl cellulose (CMC) were purchased from R\&M Chemicals (R\&M Marketing Essex, UK). Whey protein isolate (WPI) was purchased from LushProtein Pte. Ltd.

\section{Oil extraction and emulsion preparation}

Oil extraction was conducted based on a modified method of Bligh and Dryer (1959). Briefly, $100 \mathrm{~g}$ of M. oleifera seed powder was vigorously mixed with $300 \mathrm{ml}$ chloroform:methanol (1:2) solvent and the extraction process was allowed for $30 \mathrm{~min}$. The mixture was then added with $50 \mathrm{ml}$ of distilled water and mixing was continued for another $30 \mathrm{~min}$. The homogenate was then filtered through a Whatman No. 1 filter paper with the aid of a vacuum pump. The filtrate was transferred into centrifuge tubes and centrifugation was done at $3000 \mathrm{rpm}$ for $5 \mathrm{~min}$ to allow solvent separation. The oilcontaining lower layer of chloroform was collected. The oil was obtained after evaporating the solvent at $55^{\circ} \mathrm{C}$ by means of a rotary evaporator. The oil obtained was then stored in a tinted blue cap bottle at $-25^{\circ} \mathrm{C}$ for further uses

\section{Emulsion preparation}

Prior to emulsion preparation, $1.25 \%(\mathrm{w} / \mathrm{w})$ of polysaccharide solution was prepared using a deionized water that has been preheated at $80^{\circ} \mathrm{C}$ while deionized water at room temperature $\left(25 \pm 1^{\circ} \mathrm{C}\right)$ was used to prepared $5 \%(\mathrm{w} / \mathrm{w})$ emulsifier solutions. Both polysaccharide and emulsifier solutions were left overnight prior to emulsion preparation (modified from Nor Hayati et al., 2009). Six oil-in-water $(\mathrm{O} / \mathrm{W})$ emulsions were prepared by using different combinations of polysaccharide and emulsifier. The emulsifier solution $(20 \mathrm{~g}), 0.25 \mathrm{M}$ citric acid $(1 \mathrm{~g})$ and deionized water $(19 \mathrm{~g})$, were firstly premixed and homogenized using a high speed homogenizer (IKA, T 25 Ultra Turrax, Staufen, Germany). M. oleifera seed oil $(20 \mathrm{~g})$ and polysaccharide solution $(40 \mathrm{~g})$ were then added alternately into the premix, followed by homogenization for $1 \mathrm{~min}$ after each addition. Homogenization at this stage took a total of $5 \mathrm{~min}$. An ultrasonic processor (Cole Panner, CP 505, USA) was further used to homogenize the emulsion under room temperature for $3 \mathrm{~min}$ at $30 \%$ power amplitude. The actual concentrations of polysaccharide and protein in the final emulsion formulation were 0.5 and $1.0 \%$, respectively.

\section{Physicochemical analyses of emulsions}

The emulsions were firstly characterized in terms of their $\mathrm{pH}$ by using a pH meter (InoLab pH 720; Wissenschaftlich-Technische
Werkstatten GmbH, Germany). Flow behaviour of the emulsions was analysed by using a rotational viscometer (Brookfield DV-I+ viscometer, Middleboro, MA, USA) equipped with SC4-34 spindle. Viscosity measurement was carried out at 0.6, 1.5, 3.0, 6.0, 12.0 and $30.0 \mathrm{rpm}$, respectively. The first measurement was taken $2 \mathrm{~min}$ after the spindle was immersed in each sample to allow thermal equilibrium in the sample. All data was taken after $1 \mathrm{~min}$ interval for different rpm. The experimental data (rpm) obtained was converted into shear rate by using the conversion factor provided by Brookfield Engineering Laboratories (modified from Heidarinasab and Nansa, 2010). Graphs of viscosity (Pa.s) versus shear rate (1/s) were plotted to determine the flow behaviour. In addition, an apparent viscosity measured at $0.42 \mathrm{~s}^{-1}(1.5 \mathrm{rpm})$ was analysed for each emulsion.

To evaluate the emulsion stability towards phase separation or creaming stability, $10 \mathrm{~g}$ of freshly prepared emulsion was accurately weighed into a $15 \mathrm{ml}$ Teflon centrifuge tube and stored at $5^{\circ} \mathrm{C}$ for 15 days. The emulsion was then centrifuged using a high-speed centrifuge (Hettich Zentrifugation D-78532, Tuttlingen, Germany) at $3500 \mathrm{rpm}$ for $30 \mathrm{~min}$ at room temperature. The total height of each emulsion in centrifuge tube was measured. The height of separated layer (i.e. cream or aqueous) was then measured; layer $(\%)=$ (height of the separated layer/the total height of the emulsion) $\mathrm{x} 100 \%$.

To determine the radical scavenging activity on 1,1-diphenyl-2picrylhydrazyl (DPPH), $2 \mathrm{ml}$ of sample was added into $2 \mathrm{ml}$ of $0.1 \mathrm{mM}$ DPPH that dissolved in $95 \%$ methanol solution. The mixture was vigorously mixed for $10 \mathrm{~s}$ and stored in a dark room for $30 \mathrm{~min}$. The absorbance of the sample was measured at $517 \mathrm{~nm}$ wavelength and DPPH solution without sample was served as a blank. The percentage of DPPH scavenging activity was calculated as following (modified from Duan et al., 2016);

$$
\text { DPPH scavenging activity }(\%)=\frac{\left(A_{\text {blank }}-A_{\text {sample }}\right)}{A_{\text {blank }}} \times 100 \%
$$

where, $\quad \mathrm{A}_{\text {sample }}=$ absorbance of the DPPH solution after reaction with sample; $A_{\text {blank }}=$ absorbance of the DPPH solution without sample.

\section{Stability analyses of emulsions}

Turbidity loss rate was determined under an accelerated condition. The emulsion was first diluted to $0.25 \%(\mathrm{w} / \mathrm{w})$ in a $10 \%$ sugar solution. A UV/visible spectrophotometer (UV-1700 PharmaSpec, Shimadzu Scientific Instrument, Japan) which set at $500 \mathrm{~nm}$ wavelength was used to read the absorbance of the diluted emulsion taken at $5 \mathrm{~min}$ intervals for $30 \mathrm{~min}$ (Mirhosseini et al., 2009). Turbidity loss rate was calculated using the formula: In $A=\operatorname{In~} A_{0}-K_{1}$ $\mathrm{t}$, where $\mathrm{A}$ : absorbance; $\mathrm{A}_{0}$ : absorbance at time 0 , t: time; $\mathrm{K}_{1}$ : turbidity loss rate constant.

For an accelerated lipid oxidation test or known as Schaal oven test, all emulsions were stored at $60{ }^{\circ} \mathrm{C}$ in an incubator (Incubator Memmert, Germany) for 48 hours. Peroxide value (PV) and Anisidine value $(\mathrm{AV})$ were determined for the oxidized emulsions according to AOAC standard procedures (AOAC, 2000). The analyses were also involved their freshly prepared counterparts. Total oxidation (Totox) value was then calculated i.e. Totox value $=2 \mathrm{PV}+\mathrm{AV}$.

\section{Experimental design and statistical analysis}

The experimental unit of this study was a $M$. oleifera seed oil-inwater emulsion. Factors involved were different types of polysaccharide (XG, GG and $\mathrm{CMC}$ ) and emulsifier (NaCas and WPI). A $3 \times 2$ full factorial arrangement with completely randomized design was applied and resulted in a total of six treatments. All treatments were replicated for three times and the total experimental units were 18. A Two-way ANOVA was carried out to determine the main and interaction effects of polysaccharide and emulsifier on the response variables. In the case that the interaction effect of both factors was significant $(p<0.05)$, a One-way ANOVA with Tukey's multiple comparison was carried out for a simple (combined) effect. Otherwise, if the interaction effect was not significant, a One-way ANOVA with Tukey's multiple comparison was carried out to determine the main effect of each significant factor separately. All 
statistical analyses were carried out by using a Minitab 14.0 statistical software. Data was reported as mean \pm standard deviation with significance superscript letters.

\section{RESULTS AND DISCUSSION}

\section{General consideration on main and interaction effects of polysaccharide and emulsifier}

This study was designed to consider any significant interaction effects between polysaccharide and emulsifier on the emulsion physicochemical properties and stability, in addition to their respective main effects. Table 1 summarizes the two-way ANOVA statistical results for all measured responses. There were significant $(\mathrm{p}$ $<0.05$ ) interaction effects of polysaccharide and emulsifier on the $\mathrm{pH}$ apparent viscosity (at $0.42 \mathrm{~s}^{-1}$ ), creaming stability and total oxidation value of the emulsions.

Table 1 Two-way analysis of variance (ANOVA) for response variables.

\begin{tabular}{|c|c|c|c|c|}
\hline Source & Adjusted SS & Adjusted MS & $F$ & $\mathbf{p}$ \\
\hline \multicolumn{5}{|l|}{$\mathrm{pH}$} \\
\hline PS & $66.28 \times 10^{-2}$ & $33.13 \times 10^{-2}$ & 56.80 & $0.000^{\mathrm{a}}$ \\
\hline $\mathrm{E}$ & $0.27 \times 10^{-2}$ & $0.27 \times 10^{-2}$ & 0.46 & 0.510 \\
\hline Interaction & $16.10 \times 10^{-2}$ & $8.05 \times 10^{-2}$ & 13.80 & $0.001^{\mathrm{a}}$ \\
\hline \multicolumn{5}{|c|}{ Viscosity at $0.42 \mathrm{~s}^{-1}$} \\
\hline PS & $13.29 \times 10^{8}$ & $6.64 \times 10^{8}$ & 487.21 & $0.000^{\mathrm{a}}$ \\
\hline $\mathrm{E}$ & $1.91 \times 10^{8}$ & $1.91 \times 10^{8}$ & 140.16 & $0.000^{\mathrm{a}}$ \\
\hline Interaction & $4.02 \times 10^{6}$ & $2.01 \times 10^{6}$ & 147.27 & $0.000^{\mathrm{a}}$ \\
\hline \multicolumn{5}{|c|}{ Creaming stability } \\
\hline PS & 2.50 & 2.47 & 0.25 & 0.626 \\
\hline $\mathrm{E}$ & 15767.90 & 7883.95 & 798.25 & $0.000^{\mathrm{a}}$ \\
\hline Interaction & 93.80 & 49.91 & 4.75 & $0.030^{\mathrm{a}}$ \\
\hline \multicolumn{5}{|c|}{ DPPH scavenging activity } \\
\hline PS & 82.44 & 82.44 & 11.57 & $0.005^{\mathrm{a}}$ \\
\hline $\mathrm{E}$ & 512.42 & 256.21 & 35.97 & $0.000^{\mathrm{a}}$ \\
\hline Interaction & 37.78 & 18.89 & 2.65 & 0.111 \\
\hline
\end{tabular}

a Significant $(p<0.05)$. SS, sum of square; MS, mean of square; PS, polysaccharide; E, emulsifier; DPPH, 1,1-diphenyl-2-picrylhydrazyl.

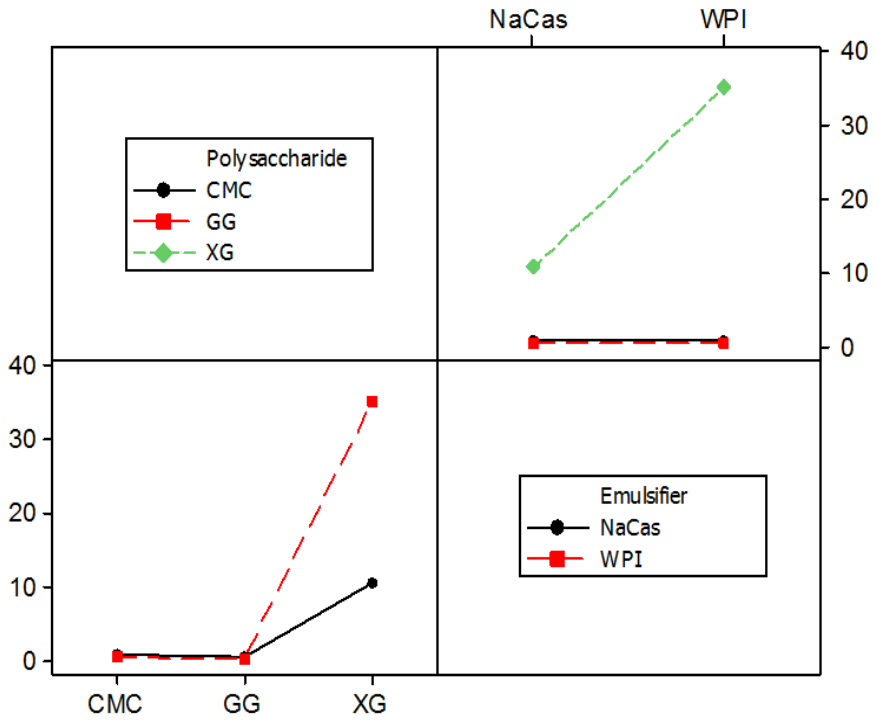

Fig. 1 Representative interaction plots between polysaccharide and emulsifier for viscosity (Pa.s). XG, xanthan gum; GG, guar gum; WPI, whey protein isolate; $\mathrm{NaCas}$, sodium caseinate.

In addition, Figure 1 provides a representative interaction plot obtained from the viscosity data. The plots exhibited lack of parallelism, indicating that the effects of polysaccharide were different when different types of emulsifier were used to stabilize the emulsions. The interaction was seemed to be pervasive that main effects could not be interpreted at their own. Therefore, the following discussion involving the said responses was focused solely on the treatments (combinations of the different levels of the two factors). In contrast, the interaction effect was not significant for the DPPH scavenging activity data, and hence, it was appropriate to infer the main effects $(p<0.05)$ of both factors separately. In addition, data for turbidity loss rate was not included in Table 1 , since neither main effects nor interaction effect of both factors were found to be significant.

\section{Physicochemical properties of $M$. oleifera seed oil-in-water emulsions}

$\mathrm{pH}$ was one of important factors that would determine the formation of a stable $\mathrm{O} / \mathrm{W}$ emulsion after emulsification process, and it was suggested that the $\mathrm{pH}$ of emulsion must be slightly above or below the isoelectric point (pI) of the emulsifier used (McClements, 2005). Suitable $\mathrm{pH}$ would determine the net charge of oil droplets covered by the emulsifier and bring stabilization effect by either electrostatic forces or steric repulsion. This would enable the emulsion to be stable towards droplet coalescence after emulsification or phase separation (creaming) within a certain period of time. In this study, the emulsifiers used were NaCas and WPI, which have pI of 4.2 (Wagoner et al., 2016) and 5.2 (pI for $\beta$-lactoglobulin, a predominant whey protein) (Ramos et al., 2017). It should be mentioned that, $\mathrm{pH}$ adjustment was not applied in this study since it was worthwhile to infer any variations in $\mathrm{pH}$ of the emulsions due to the different treatments applied, since levels of other ingredients were set at constant, including citric acid. The use of $1 \%(0.25 \mathrm{M})$ citric acid was found to provide the resultant emulsions to be at the $\mathrm{pH}$ range of 4.72-5.40. As depicted in Table 1, the $\mathrm{pH}$ value was significantly ( $\mathrm{p}<$ 0.05 ) influenced by the polysaccharide-emulsifier interaction. Upon emulsification, the $M$. oleifera seed oil was added to the aqueous phase containing emulsifier at $\mathrm{pH} 4.0$ since $1 \%(0.25 \mathrm{M})$ citric acid was used. This value was deviated below the $\mathrm{pI}$ of both emulsifiers and at the same time, no notable influence of the emulsifiers on the $\mathrm{pH}$ was observed. The oil was dispersed into tiny droplets as emulsifier formed a primary layer around the droplet surface. Due to the fact that the amino groups were positively charged $\left(-\mathrm{NH}_{3}{ }^{+}\right)$at $\mathrm{pH}$ below the $\mathrm{pI}$ of the protein whilst the carboxyl groups were neutral ($\mathrm{COOH})$, the oil droplets in all emulsions were suggested to be initially existed in their net positive charge. With addition of anionic polysaccharides including $\mathrm{XG}$ and $\mathrm{CMC}$, an interaction between emulsifier (protein) and polysaccharide was presumed to form a secondary layer around the protein-coated droplet surface (Xu et al. 2017; Sriprablom et al., 2019).). As proven by the present result depicted in Table 1 , the $\mathrm{pH}$ value was significantly $(\mathrm{p}<0.05)$ influenced by the polysaccharide-emulsifier interaction. Magnitude of the interaction would however depend on the chemical nature of the polysaccharide. This interaction was believed to influence the final $\mathrm{pH}$ of the resultant emulsion as it would neutralize the positive charges and increase the $\mathrm{pH}$. This gave the final $\mathrm{pH}$ of the emulsions to be in the range from 4.72 to 5.40 (Table 2). Nevertheless, the net charge of the oil droplets was highly depended on the pI of the protein. For instance, oil droplets in the XG-WPI emulsion with $\mathrm{pH} 4.98$ were believed to be in their net positive charge as the $\mathrm{pH}$ was below the protein $\mathrm{pI}$ (5.2) and vice versa for XG-NaCas emulsion. It was well accepted that, an effective polysaccharide-protein interaction would contribute to electrostatic stabilization effect among droplets, promoting their long term stability. It was however, important to highlight that the extent of this electrostatic stabilization effect was apparently $\mathrm{pH}$-dependent. Relationship between $\mathrm{pH}$ and emulsion stability was further discussed in the following section by focusing on stability of $M$. oleifera seed oil-in-water emulsions.

Table $2 \mathrm{pH}$, viscosity (at $0.42 \mathrm{~s}^{-1}$ ) and turbidity loss rate of $M$. oliefera seed oil-in-water emulsions.

\begin{tabular}{|c|c|c|c|c|}
\hline PS & $E$ & pH & $\begin{array}{c}\text { Viscosity } \\
\text { (mPa.s) }\end{array}$ & $\begin{array}{c}\text { Turbidity } \\
\text { loss rate } \\
\left(\times 10^{-3}\right)\end{array}$ \\
\hline$X G$ & NaCas & $4.72^{\mathrm{c}} \pm 0.05$ & $10.75^{b} \pm 2.61$ & $3.3^{a} \pm 0.2$ \\
\hline GG & NaCas & $5.20^{\mathrm{a}} \pm 0.07$ & $0.55^{c} \pm 0.21$ & $1.9^{a} \pm 0.6$ \\
\hline CMC & NaCas & $5.40^{\mathrm{a}} \pm 0.03$ & $0.85^{c} \pm 0.07$ & $1.3^{a} \pm 0.7$ \\
\hline
\end{tabular}


$X G$

GG

\section{WPI}

WPI WPI

\begin{abstract}
$4.98^{\mathrm{b}} \pm 0.04$
\end{abstract}
$35.10^{\mathrm{a}} \pm 1.13$

$0.35^{\mathrm{c}} \pm 0.07$

$1.2^{\mathrm{a}} \pm 0.8$

$0.65^{\circ} \pm 0.07$

$2.5^{\mathrm{a}} \pm 0.1$ $5.19^{\mathrm{a}} \pm 0.08$

$2.3^{\mathrm{a}} \pm 0.7$

Data is presented as average from triplicate results $(n=3)$. ${ }^{\text {a-c }}$ Means with different superscripts within the same column are significantly different $(p<0.05)$. PS, polysaccharide; $E$, emulsifier; $X G$, xanthan gum; GG, guar gum; WPI, whey protein isolate; NaCas, sodium caseinate.

Flow behaviour of the emulsion was studied through evolution of viscosity as a function of shear rate as demonstrated by representative flow curves in Figure 2. Regardless of different polysaccharides and emulsifiers used, all emulsions showed a shear-thinning behaviour in which their viscosity was decreased gradually across shear rate. When shear force was applied, the oil droplets could rearrange themselves in a direction that parallel to the shear force and big flocculated droplets (flocs) could breakdown into individual small droplets. The droplets were flowed easily as a result of the low resistance that arose from droplet-droplet interactions, leading to the decrease in viscosity (De Cassia Da Fonseca et al., 2009). However, the viscosity of all emulsions was quite similar at higher shear rate. This was due to all flocs were completely disrupted so that only individual droplets were remained (Samavati et al., 2012).

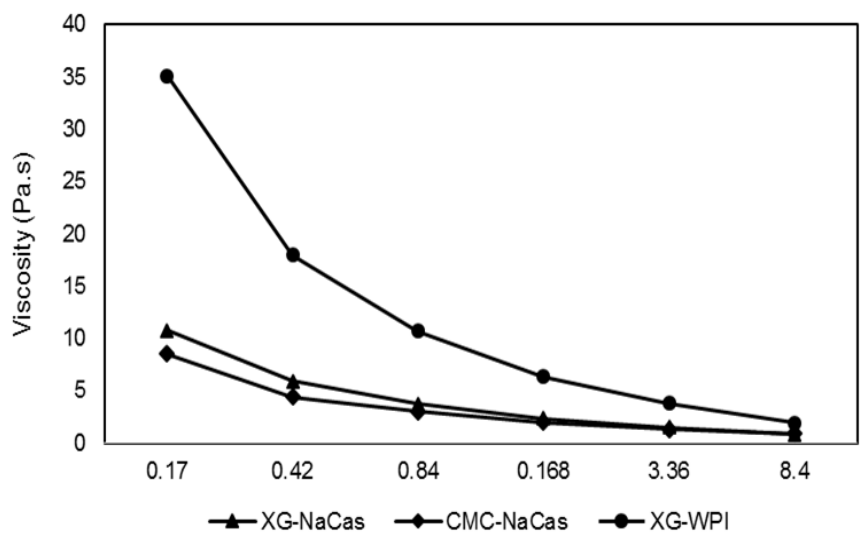

Fig. 2 Evolution of viscosity as a function of shear rate for representative $M$. oleifera seed $\mathrm{O} / \mathrm{W}$ emulsions. Data points are presented as mean from replicate results $(n=2)$. See Table 2 for sample abbreviations.

To estimate the emulsion viscosity under a quiescent condition, an apparent viscosity at $0.42 \mathrm{~s}^{-1}$ was determined as depicted in Table 2, which was significantly $(\mathrm{p}<0.05)$ affected by the interaction between polysaccharide-emulsifier used. Emulsion prepared with WPI and XG has recorded the highest viscosity and was significantly $(\mathrm{p}<0.05)$ different from others. Sriprablom et al. (2019) reported that, at $\mathrm{pH}$ below the $\mathrm{pI}$ of emulsifier, addition of $\mathrm{XG}$ would lead to the formation of protein-polysaccharide complex, which could substantially increase the emulsion rheology (i.e. viscosity, in the present case). On top of that, the high viscosity of the emulsion was possibly due to the emulsion droplet size. Fine emulsions were believed to have higher viscosity than corresponding coarse emulsions (Pal, 1996).

In this study, DPPH scavenging activity was used to estimate antioxidant activity of the emulsions. As mentioned earlier, there was no significant interaction effect between polysaccharide and emulsifier used. However, main effect of both factors was seemed to be significant $(\mathrm{p}<0.05)$ (Table 1$)$. As compared to NaCas, WPI showed greater effect on the antioxidant activity of the emulsion (Table 3). This could be attributed to sulfhydryl groups of WPI which were capable to quench free-radicals. Besides, XG also performed the highest antioxidant activity amongst the polysaccharides, regardless of emulsifier used. This was due to the fact that XG has increased the viscosity of the aqueous phase and hindered the diffusion of prooxidants to the oil droplet surfaces (Chen et al., 2016). Apart from that, side chains of pyruvate residue of XG were also believed to have a scavenging capacity on the DPPH free radicals.
Table 3 1,1-diphenyl-2-picrylhydrazyl (DPPH) scavenging activity (\%) of $M$. oliefera seed oil-in-water emulsions

\begin{tabular}{lccc}
\hline Polysaccharide & \multicolumn{3}{c}{ Emulsifier } \\
\cline { 2 - 4 } & NaCas & WPI & Mean \\
\hline XG & 39.84 & 41.52 & $40.68^{\mathrm{A}}$ \\
GG & 24.45 & 32.78 & $28.61^{\mathrm{B}}$ \\
CMC & 28.89 & 31.73 & $30.31^{\mathrm{B}}$ \\
\hline Mean & $31.06^{\mathrm{b}}$ & $35.34^{\mathrm{a}}$ & \\
\hline
\end{tabular}

Data is presented as average from triplicate results $(n=3)$. A-B/a-b Means with different superscripts within the same column/row are significantly different $(p<0.05)$. See Table 2 for sample abbreviations.

\section{Stabilty of M. oleifera seed oil-in-water emulsions}

Turbidity loss rate was an indicator to determine cloud stability of emulsion under accelerated (diluted form) condition. However, the present results indicated that there was no significant interaction as well as main effect of both polysaccharide and emulsifier on this particular response (Table 1). Consequently, no significant difference among samples was observed, with their narrow range of turbidity loss rate values $\left(1.2-3.3 \times 10^{-3}\right)$ (Table 2$)$. This cloud stability was an important criterion for a beverage-type functional emulsion as the emulsion should maintain its cloudiness after dilution with water prior to consumption. It was seemed that all polysaccharide-emulsifier combinations could provide this cloud stability to a similar extent. Furthermore, Mohagheghi et al. (2011) reported that use of polysaccharide was necessary to provide the least loss rate of turbidity. Polysaccharides could provide a protection layer on the interfacial surface of the emulsion and thus, preventing a change in the refractive index of dispersed oil droplets which in turn maintaining the turbidity.

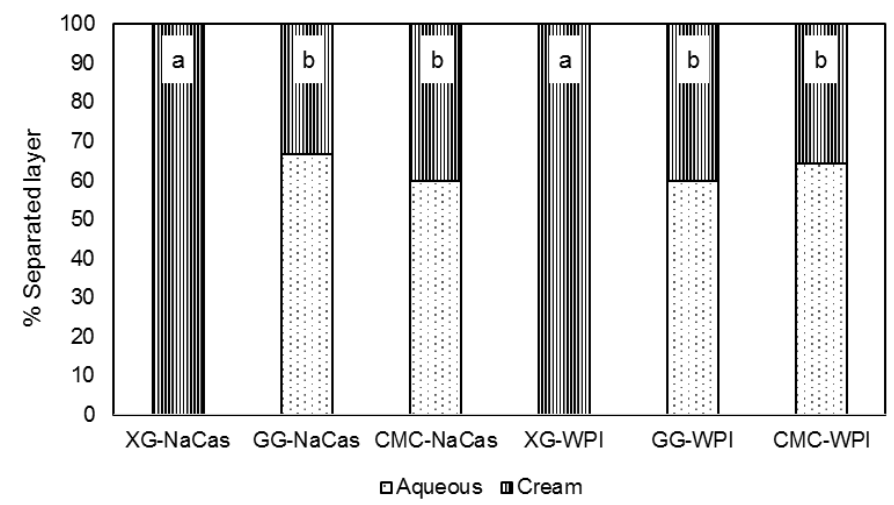

Fig. 3 Creaming stability of $M$. oleifera seed oil-in-water emulsions after storage $\left(15\right.$ days, $\left.4^{\circ} \mathrm{C}\right)$. Data are presented as average from triplicate results $(n=3)$. a-b Means with different superscripts are significantly different $(p<0.05)$ for cream layer. See Table 2 for sample abbreviations.

Differently, results of creaming stability showed that the effect of emulsifier was significantly $(p<0.05)$ depended on types of polysaccharides used, revealing the importance of their interaction at oil-water interphase. All emulsions showed separated aqueous layers (or synerisis) except for XG emulsions (Figure 3). A remarkable creaming stability was demonstrated by $\mathrm{XG}$ emulsions, due to a hydrodynamic stabilizing effect (McClements, 2005). This effect was caused by thickening and increasing the viscosity of the aqueous phase by the addition of $\mathrm{XG}$ at a sufficient concentration (i.e. $0.5 \%$ for the present case). Upon dispersion, high molecular weight of $\mathrm{XG}$ molecules formed complex aggregates through hydrogen bonds and polymer entanglement (Paximada et al., 2016). Because of these high ordered networks and entanglements, XG caused the increase in viscosity of the emulsion aqueous phase, as evidenced by the viscosity result. At high viscosity, oil droplets in the dispersed phase were barely moved and no creaming was observed after centrifugation process. In relation to the $\mathrm{pH}$ of the emulsions, as discussed earlier, the protein-coated droplets in the emulsions were proposed to be initially existed in their positive charges. As XG was added during 
emulsification process, attractive electrostatic interactions between the anionic groups (-COO-) on the XG molecules and the exposed amino group $\left(\mathrm{NH}^{3+}\right)$ of the proteins were occurred, leading to the formation of secondary layers around the droplets (Sriprablom et al., 2019). This has resulted in the formation of strong barrier layers that kept the oil droplets apart by a steric repulsion effect and thus, maintaining their stable dispersed state even under an accelerated condition (i.e. application of centrifugation force after 15 days of storage). This interaction effect has recently been reported to also benefit the whey protein-stabilized emulsions containing other types of anionic polysaccharide, including flaxseed gum (Xu et al., 2017) and pectin (Albano et al., 2018).

On the other hand, there was a notable synerisis (with the occurrence of aqueous layer) happened in the emulsions with GG and CMC. By considering low viscosity of their respective emulsions (Table 2), it was seemed that the protein-polysaccharide interaction existed in these emulsions could not provide sufficient barrier layers between the adjacent droplets to withstand the applied centrifugation force and thus, becoming unstable towards creaming. It was suggested that, when the $\mathrm{pH}$ values of emulsion near the $\mathrm{pI}$ of proteins were observed for GG-WPI and CMC-WPI emulsions, the droplet charges were insufficient to generate an electrostatic repulsion to overcome various attractive droplet-droplet interactions, e.g. van der Waals and hydrophobic interactions. With regards to negatively-charged carboxymethyl side group $\left(\mathrm{CH}_{2} \mathrm{CO}=\mathrm{O}\right)$ of $\mathrm{CMC}$, the proteinpolysaccharide interaction was also expected to be occurred in the resultant emulsions but apparently the interaction was not significant enough to provide an effective steric barrier between the neighbouring droplets, probably due to insufficient CMC concentration. Meanwhile, due to non-ionic nature of GG, it was very unlikely for GG and protein molecules to interact to each other to form secondary layers around the protein-coated droplets. This situation was believed to cause exclusion of non-complexed GG from the gap between adjacent droplets when the centrifugation force was applied. The region between the droplets was depleted for GG and hence, the droplets were tended to flocculate due to the weak electrostatic repulsion. This has finally favoured the creaming process. Many previous studies have also demonstrated emulsion destabilization due to depletion in flocculation mechanism, including Neirynck et al. (2007) and Xu et al. (2017) for emulsions stabilized by GG-NaCas and fenugreek gumWPI, respectively. These drawbacks demonstrated by CMC and GG most conceivably could be overcome at higher polysaccharide concentration i.e. $>0.5 \%$ for the present case which might pronouncedly increase the viscosity of the emulsion aqueous phase.

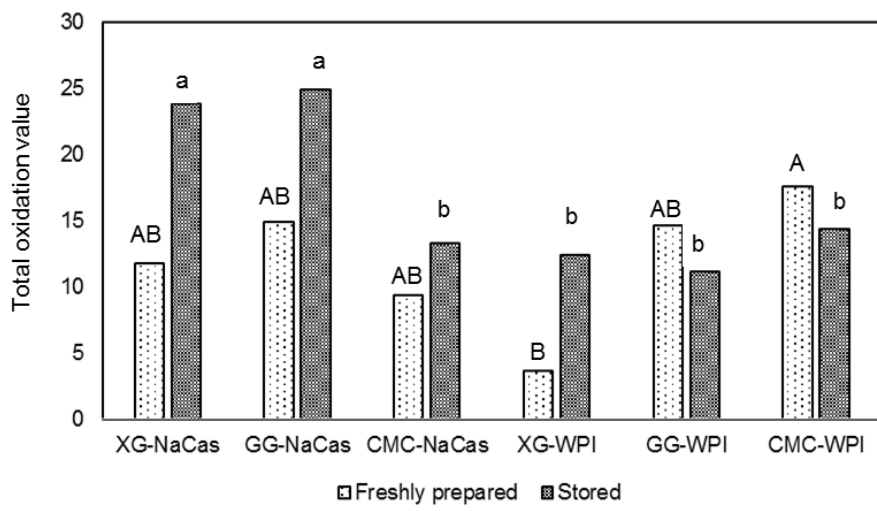

Fig. 4 Total oxidation value of $M$. oleifera seed o/w emulsions. Data are presented as average from triplicate results $(n=3)$. A-B/a-b Means with different superscripts within the same group of emulsion, are significantly different $(p<0.05)$. See Table 1 for sample abbreviations.

In terms of oxidative stability, total oxidation (Totox) value in this study was more influenced by peroxide value rather than $p$-anisidine value. The peroxide value for freshly prepared emulsions was ranged in $3.0-8.5 \mathrm{mEq} / \mathrm{kg}$ and progressed to $5.0-12.7 \mathrm{mEq} / \mathrm{kg}$ after storage at $60^{\circ} \mathrm{C}$ for 48 hours. It was suggested that hydroperoxides formed in all emulsions were not much degraded into secondary oxidation products as low $p$-anisidine values were recorded (i.e. $0.4-0.7$ and $0.5-2.3$ for freshly prepared and oxidized emulsions, respectively). As seen in Figure 4, emulsion that prepared with CMC-WPI exhibited the highest Totox value whilst the one prepared with XG-WPI exhibited the lowest value. This was because of WPI has antioxidant properties that attributable to its sulfhydryl groups that would bind to pro-oxidant and thus, inhibiting the oxidation process. In addition, sufficiently thick interfacial layers formed by XG-WPI complex were also appeared to be effective to prevent diffusion of pro-oxidants from $\mathrm{O} / \mathrm{W}$ interphase to the dispersed oil droplets. Apart from that, this complex interaction of protein-polysaccharide was also able to inactivate peroxyl radicals in the emulsion and hence, preventing the formation of secondary oxidation products from developing. This mutual antioxidant effect by both WPI and XG was well supported by the highest DPPH scavenging activity shown by the respective emulsions (Table 3 ).

Interestingly, the emulsions prepared with WPI showed lower Totox value after storage. This might be due to the storage temperature $\left(60^{\circ} \mathrm{C}\right)$ applied. Tong et al. (2000) stated that whey proteins could inhibit lipid oxidation by inactivating peroxyl radicals and this function would be enhanced when the emulsion was subjected to heat due to exposure of more free-radical scavenging sulfhydryl groups. O'Dywer et al. (2013) also demonstrated a similar finding whereby the increase in storage temperature would enhance the oxidative stability of whey protein stabilized emulsion.

\section{CONCLUSION}

This study demonstrated a high possibility of producing a functional food emulsion using a highly valued $M$. oleifera seed oil as the oil dispersed phase. The findings revealed that complex interactions between polysaccharide and emulsifier were significant in influencing physicochemical properties and stability of the prepared emulsions. Of all polysaccharide-emulsifier combinations, XG-WPI combination could provide the emulsion with the most desired properties. This was due to the positive interaction effect on emulsion viscosity which indirectly led to a good stability towards creaming and inhibition of lipid oxidation. It was also worth mentioning that, a good stability towards lipid oxidation would fairly reflect a good preservation of medicinal properties of $M$. oleifera seed oil in such food colloid system.

\section{ACKNOWLEDGEMENT}

This study was financially supported by Universiti Malaysia Terengganu.

\section{REFERENCES}

Abdulkadir, A. R., Zawawi, D. D., Jahan, M. S. 2016. Proximate and phytochemical screening of different parts of Moringa oleifera. Russian Agricultural Sciences, 42, 34-36.

Albano, K. M., Vânia, R., Nicoletti, V. R. 2018. Ultrasound impact on whey protein concentrate-pectin complexes and in the $\mathrm{O} / \mathrm{W}$ emulsions with low oil soybean content stabilization. Ultrasonics Sonochemistry, 41, 562-571.

AOAC. 2000. Official Method of Analysis. 17 ${ }^{\text {th }}$ Edition. Arlinton: Association of Official Analytical Chemists's Press.

Bhatnagar, A. S., Gopala, Krishna, A. G. 2013. Natural antioxidants of the Jaffna variety of Moringa oleifera seed oil of Indian origin as compared to other vegetable oils. Grasas y Aceites, 64, 537-545.

Bhutada, P. R., Jadhav, A. J., Pinjari, D. V., Nemade, P. R., Jain, R. D. 2016. Solvent assisted extraction of oil from Moringa oleifera Lam. seeds. Industrial Crops Production, 82, 74-80.

Bligh, E. G., Dryer, W. J. 1959. A rapid method of total lipid extraction and purification. Canadian Journal of Biochemistry and Physiology, 37, 911917

Chen, X., Li, X., Zhao, Q., Selomulya, C., Zhu, X., Xiong, H. 2016. Physical and oxidative stabilities of $\mathrm{o} / \mathrm{w}$ emulsions formed with rice dreg protein hydrolysate: Effect of xanthan gum rheology. Food Bioprocess Technology, 9,1380-1390.

De Cássia Da Fonseca, V., Haminiuk, C. W. I., Izydoro, D. R., Waszczynskyj, N., De Paula Scheer, A., Sierakowski, M. R. 2009. Stability and rheological behaviour of salad dressing obtained with whey and different combinations 
of stabilizers. International Journal of Food Science and Technology, 44, 777-783.

Duan, X., Li, M., Ma, H., Xu, X., Jin, Z., Liu, X. 2016. Physicochemical properties and antioxidant potential of phosvitin-resveratrol complexes in emulsion system. Food Chemistry, 206, 102-109.

Erçelebi, E. A., Ibanoğlu, E. 2009. Rheological properties of whey protein isolate stabilized emulsions with pectin and guar gum. European Food Research and Technology, 229, 281-286.

Ghafar, F., Tengku Nazrin, T. N. N., Mohd Salleh, M. R., Nor Hadi, N., Ahmad, N., Hamzah, A. A., Mohd Yusof, Z. A., Azman, I. N. 2017. Total phenolic content and total flavonoid content in Moringa oleifera seed. Science Heritage Journal, 1, 23-25.

Heidarinasab, A., Nansa, V. M. 2010. Time independent behavior of tomato paste. International Journal of Biology Biomolecular, Agricultural, Food and Biotechnological Engineering, 4, 142-145.

Liu, L., Zhao, Q., Liu, T., Kong, J., Long, Z., Zhao, M. 2012. Sodium caseinate/carboxymethyl cellulose interactions at oil-water interface: Relationship to emulsion stability. Food Chemistry, 132, 1822-1829.

Liu, S., Liu, F., Xue, Y., Gao, Y. 2016. Evaluation on oxidative stability of walnut oil beverage emulsions. Food Chemistry, 203, 409-416.

McClement, D. J. 2005. Food emulsions: Principle, Practice and Techniques. New York: CRC Press LLC.

Mirhosseini, H., Tan, C. P., Aghlara, A., Hamid, N. S. A., Yusof, S., Chern, B H. 2008. Influence of pectin and CMC on physical stability, turbidity loss rate, cloudiness and flavor release of orange beverage emulsion during storage. Carbohydrate Polymers, 73, 83-91.

Mohagheghi, M., Rezaei, K., Labbafi, M., Ebrahimzadeh Mousavi, S.M. 2011. Pomegranate seed oil as a functional ingredient in beverages. European Journal of Lipid Science and Technology, 113, 730-736.

Nayebzadeh, K., Chen, J., Mousavi, S. M. 2007. Interactions of WPI and xanthan in microstructure and rheological properties of gels and emulsions. International Journal of Food Engineering, 3, 1-17.

Nor Hayati, I., Che Man, Y. B., Tan, C.P., Nor Aini, I. 2009. Droplet characterization and stability of soybean oil/palm kernel olein o/w emulsions with the presence of selected polysaccharides. Food Hydrocolloids, 22, 233 243.

Neirynck, N., Van lent, K., Dewettinck, K., Van der Meeren, P. 2007. Influence of $\mathrm{pH}$ and biopolymer ratio on sodium caseinate-guar gum interactions in aqueous solutions and in o/w emulsions. Food Hydrocolloids, $21,862-869$.
O’Dwyer, S. P., O’Beirne, D., Eidhin, D. N., O'Kennedy, B. T. 2013. Effects of sodium caseinate concentration and storage conditions on the oxidative stability of oil-in-water emulsions. Food Chemistry, 138, 1145-1152.

Pal, R. 1996. Effect of droplet size on the rheology of emulsions. AIChE Journal, 42, 3181-3190.

Paximada, P., Koutinas, A. A., Scholten, E., Mandala, I. G. 2016. Food hydrocolloids effect of bacterial cellulose addition on physical properties of WPI emulsions. Comparison with common thickeners. Food Hydrocolloids, 54, 245-254.

Ramos, O. L., Pereira, R. N., Martins, A., Rodrigues, R., Fuciños, C., Teixeira, J. A., Pastrana, L., Malcata, F.X., Vicente, A. A. 2017. Design of whey protein nanostructures for incorporation and release of nutraceutical compounds in food. Critical Reviews in Food Science and Nutrition, 57, $1377-1393$.

Samavati, V., Emam-Djomeh, Z., Mohammadifar, M. A., Omid, M., Mehdinia, A. L. I. 2012. Stability and rheology of dispersions containing polysaccharide, oleic acid and whey protein isolate. Journal of Texture Studies, 43, 63-76.

Semenova, M. 2017. Protein-polysaccharide associative interactions in design of tailor-made colloidal particles. Current Opinion in Colloid and Interphase Science, 28, 15-21.

Sriprablom, J., Luangpituksa, P., Wongkongkatep, J., Pongtharangkul, T., \& Suphantharika, M. (2019). Influence of $\mathrm{pH}$ and ionic strength on the physical and rheological properties and stability of whey protein stabilized o/w emulsions containing xanthan gum. Journal of Food Engineering, 242, 141 152.

Tong, L., Sasaki, S., McClements, D. J., Decker, E. 2000. Antioxidant activity of whey in a salmon oil emulsion. Journal of Food Science, 65, 1325-1329.

Udechukwu, M. C., Abbey, L., Nwodo, U., Udenigwe, C. C. 2018. Potential of Moringa oleifera seeds and leaves as functional food ingredients for human health promotion. Journal of Food and Nutrition Research, 57, 1-14.

Wagoner, T., Vardhanabhuti, B., Foegeding, E. A. 2016. Designing whey protein-polysaccharide particles for colloidal stability. Annual Review of Food Science and Technology, 7, 93-116.

Xu, D., Qi, Y., Wang, X., Li, X., Wang, S., Cao, Y., Wang, C., Sun, B., Decker, E. A., Panya, A. 2017. Influence of flaxseed gum on the microrheological properties and physicochemical stability of whey protein stabilized $\beta$-carotene emulsions. Food \& Function, 8, 415-423. 